OPEN ACCESS

Edited by: Jordan Orange, Baylor College of Medicine, USA

Reviewed by: Isabelle Meyts, KU Leuven, Belgium Sergio Rosenzweig, National Institutes of Health, USA

*Correspondence:

Carol Saunders csaunders@cmh.edu

Specialty section: This article was submitted to Pediatric Immunology, a section of the journal Frontiers in Pediatrics

Received: 06 January 2017 Accepted: 22 March 2017 Published: 19 April 2017

Citation: Mettman D, Thiffault I, Dinakar C and Saunders C (2017) Immunodeficiency-Associated Lymphoid Hyperplasia As a Cause of Intussusception in a Case of Activated PI3K- $\delta$ Syndrome.

Front. Pediatr. 5:71. doi: 10.3389/fped.2017.00071

\section{Immunodeficiency-Associated Lymphoid Hyperplasia As a Cause of Intussusception in a Case of Activated PI3K- $\delta$ Syndrome}

\author{
Daniel Mettman', Isabelle Thiffault ${ }^{1,2,3}$, Chitra Dinakar ${ }^{4}$ and Carol Saunders ${ }^{1,2,3 *}$ \\ ${ }^{1}$ Department of Pathology and Laboratory Medicine, University of Kansas School of Medicine, Kansas City, MO, USA, \\ ${ }^{2}$ Center for Pediatric Genomic Medicine, Children's Mercy Hospital, Kansas City, MO, USA, ${ }^{3}$ Department of Pathology \\ and Laboratory Medicine, Children's Mercy Hospitals, Kansas City, MO, USA, ${ }^{4}$ Stanford University School of Medicine, \\ Stanford, CA, USA
}

Activated $\mathrm{PI} 3 \mathrm{~K}-\delta$ syndrome refers to a recently described primary immunodeficiency syndrome consisting of recurrent sinopulmonary infections, lymphadenopathy, mucosal lymphoid aggregates, increased susceptibility to Epstein-Barr virus and cytomegalovirus, and increased incidence of B-cell lymphomas. Variants in PIK3CD, which encodes the phosphatidylinositol-4,5-bisphosphate 3-kinase catalytic subunit delta isoform, enhance membrane association and kinase activity, resulting in increased signal transduction through the PI3K-Akt pathway. Whole-exome sequencing revealed a pathogenic PIK3CD variant in a patient with history of immunologic impairment, recurrent sinopulmonary infections, and lymphoid hyperplasia presenting as intussusception. This case illustrates that while lymphoid hyperplasia secondary to immunodeficiency is most often unsurprising and non-threatening, it can present as an emergency-like intussusception.

Keywords: lymphoid hyperplasia, PIK3CD, sinopulmonary infections, primary immunodeficiency, B-cell lymphomas

\section{INTRODUCTION}

Pathogenic variants in a number of genes cause primary immunodeficiencies (PIDs), which predispose to infections. One such PID, activated PI3K- $\delta$ syndrome (APDS), is associated with dominant gain-of-function variants in PIK3CD encoding $\mathrm{p} 110 \delta$, the catalytic subunit of phosphoinositide 3-kinase $\delta$. This protein is selectively expressed in leukocytes and is critical for lymphocyte biology. In mammals, there are three classes of PI(3)K that are distinct in their mechanisms of regulation, substrate specificity, and structure. Among the class I PI(3)K molecules, only p1108 (OMIM: 602839) is restricted to leukocytes and has specialized functions in adaptive immunity (1-5). Various germline or de novo, heterozygous gain-of-function variants in the PIK3CD gene have been reported in patients presenting with sinopulmonary infections, lymphadenopathy, nodular lymphoid hyperplasia, and cytomegalovirus and/or Epstein-Barr virus viremia $(6,7)$. One such variant, E1021K, has been described in several affected individuals $(6,8-12)$. Here, we report a patient with p.E1021K with a unique presentation.

In 2009, a 6-year-old boy presented with abdominal pain, constipation, and encopresis. Imaging revealed intussusception that was only temporarily reduced with air enemas, necessitating an emergency laparotomy that revealed a causative ileocecal valve mass. On microscopic examination, the mass consisted of non-granulomatous hyperplastic lymphoid tissue that was 
determined to be non-neoplastic by immunohistochemistry and fluorescent in situ hybridization. Surgical resection resolved the symptoms, but in the context of the patient's medical history the lymphoid hyperplasia could not simply be ascribed to infection. His birth and past medical history revealed that after an uneventful term gestation and delivery, his development was unremarkable until cessation of breastfeeding at 2 years of age, after which he began to experience recurrent episodes of otitis media and sinusitis. That year he developed pulmonary symptoms that required a hospitalization and which eventually led to the development of bronchiectasis. Throughout the following 3 years, he continued to experience upper respiratory infections and recurrent otitis media with hearing impairment secondary to tympanic membrane rupture for which he underwent bilateral myringotomy with tympanostomy tube placement, tonsillectomy, adenoidectomy, and sinus evacuation.

Pertinent negative testing included Histoplasma serology, total complement activity, sweat chloride testing for cystic fibrosis, granulocyte oxidative burst testing for chronic granulomatous disease, and a tracheal cilia biopsy for ciliary dyskinesia. Quantitative total immunoglobulin and immunoglobulin subclass assays were repeatedly within normal limits except for consistently elevated levels of IgM (Table 1). However, while he demonstrated adequate functional response to protein antigens, despite repeated vaccination with conjugate pneumococcal vaccine and the pneumococcal polysaccharide vaccines, his pneumococcal titers were suboptimal, indicating functional antibody deficiency. Flow cytometric quantitative analysis of lymphocytes revealed a reduced number of $T$ cells and a persistently decreased CD4:CD8 ratio. He had a low normal number of B cells, mildly low number of memory $B$ cells, and a proportionately mild decrease in class-switched memory B cell subset (Table 1), but without evidence of class-switch blockage. His $\mathrm{T}$ cell function assay demonstrated evidence of impairment with low response to mitogens, normal response to Candida antigen, and no response to tetanus antigen. Testing for toll-like receptor function and the mannan-binding lectin pathway was unremarkable. Replacement subcutaneous gammaglobulin therapy was started in light of his history of recurrent sinopulmonary infections causing significant morbidity, functional antibody deficiency, and diminished $\mathrm{T}$ cell numbers and function. He subsequently developed significant cervical and occipital lymphadenopathy that was non-tender and not associated with any systemic symptoms, suggestive of infectious etiology.

\section{MATERIALS AND METHODS}

\section{Microarray}

Microarray-based comparative genomic hybridization was performed using a custom microarray chip design with $\sim 180,000$

TABLE 1 | Immune evaluation of patient with PIK3CD-related disease.

\begin{tabular}{|c|c|c|c|c|c|c|}
\hline Parameters & Normal & 2015 & 2014 & 2013 & 2012 & 2011 \\
\hline Abs lymph $(\mu \mathrm{L})$ & $1.50-4.90$ & 1.09 & 0.94 & 0.82 & 0.54 & 1.17 \\
\hline WBC $(\mu \mathrm{L})$ & $4.50-14.50$ & - & - & - & 6.92 & $4.26 \mathrm{~L}$ \\
\hline Lymph \% & $95-100 \%$ & - & - & - & 16 & 21.1 \\
\hline F lymph abs $\left(\mathrm{mm}^{3}\right)$ & $1,400-4,000$ & - & - & - & 1,107 L & $899 \mathrm{~L}$ \\
\hline CD45 \% & $95-100 \%$ & 96.05 & 99.83 & 98.31 & 98.68 & 99.9 \\
\hline T cells plus (CD2+) \% & $95-100 \%$ & 76 & - & - & 80 & 86 \\
\hline T cells plus (CD2+) abs & $1,100-3,800$ & $829 \mathrm{~L}$ & - & - & $886 \mathrm{~L}$ & $773 \mathrm{~L}$ \\
\hline T cells plus (CD3+) \% & $\%$ & 67 & 73 & 70 & 75 & 78 \\
\hline T cells plus (CD3+) abs & $900-2,900$ & $730 \mathrm{~L}$ & $687 \mathrm{~L}$ & $575 \mathrm{~L}$ & $830 \mathrm{~L}$ & $701 \mathrm{~L}$ \\
\hline T helper cells \% & $95-100 \%$ & 27 & 31 & 32 & 39 & 38 \\
\hline T helper cells abs & $450-1,600$ & $294 \mathrm{~L}$ & $292 \mathrm{~L}$ & $263 L$ & $432 \mathrm{~L}$ & $342 \mathrm{~L}$ \\
\hline T cytotoxic cells \% & $\%$ & 37 & 39 & 34 & 32 & 36 \\
\hline T cytotoxic cells abs & $300-1,000$ & 403 & 367 & $279 \mathrm{~L}$ & 354 & 324 \\
\hline Helper/cytotoxic ratio (CD4/CD8) & $1.20-2.99$ & $0.73 \mathrm{~L}$ & $0.79 \mathrm{~L}$ & $0.94 \mathrm{~L}$ & 1.22 & $1.06 \mathrm{~L}$ \\
\hline \multicolumn{7}{|l|}{ T cell interpretation } \\
\hline Total B cells (CD19+) \% & $\%$ & 13 & - & 16 & 15 & 12 \\
\hline Total B cells (CD19+) abs & $100-700$ & 142 & - & 131 & 166 & 108 \\
\hline TBNK interpretation & & & - & - & - & - \\
\hline Natural killer cells \% & $\%$ & 15 & - & - & 9 & 8 \\
\hline Natural killer cells abs & 80-662 & 164 & - & - & 100 & $72 \mathrm{~L}$ \\
\hline Activated T cells (CD25+) \% & $\%$ & 10 & - & - & 14 & 12 \\
\hline Activated T cells (CD25+) abs & & 109 & - & - & 155 & 108 \\
\hline Activated T cells (HLA-DR+) \% & $\%$ & 9 & - & - & 16 & 12 \\
\hline Activated T cells (HLA-DR+) abs & & 98 & - & - & 177 & 108 \\
\hline Natural killer T cells (CD3+/CD16, 56+) \% & $\%$ & 8 & - & - & 6 & 3 \\
\hline Natural killer T cells abs & & 87 & - & - & 66 & 27 \\
\hline \multicolumn{7}{|l|}{ Serum immunoglobulins (mg/dL) } \\
\hline $\lg G$ & $608-1,229$ & & 1,110 & 1,290 & 593 & 666 \\
\hline $\lg A$ & 32-234 & - & - & - & 339 & 271 \\
\hline $\lg \mathrm{M}$ & $46-230$ & - & - & - & 140 & 295 \\
\hline $\lg E$ & $0-126$ & - & - & - & - & $<2.0$ \\
\hline
\end{tabular}

L, low. 
oligonucleotide probes based on human genome sequence (hg18). Chips were designed by Baylor College of Medicine (Houston, TX, USA) and manufactured by Agilent Technologies (Santa Clara, CA, USA). Analysis software is based on human genome build 36 (hg18).

\section{Molecular Genetics}

Exome sequencing was performed on a research basis for this patient and his healthy parents following informed consent. Genomic DNA was extracted from peripheral blood mononuclear cells using a Chemagen MSM1 robot (Perkin Elmer, Baesweiler, Germany). DNA was prepared utilizing the KAPA Biosystems library preparation kit (KAPA Biosystems, Woburn, MA, USA) followed by Illumina TruSeqExome enrichment (Illumina, San Diego, CA, USA). The proband's sample was sequenced to $15.2 \mathrm{~Gb}$ for an average depth of $\sim 120 \times$. Bidirectional sequence was assembled and aligned to reference sequence (GRCh37/UCSC hg19). Alignment and variant calling was performed as previously published (13-15). Briefly, using custom-developed software, RUNES and VIKING, variants were filtered to $1 \%$ minor allele frequency, then prioritized by the American College of Medical Genetics categorization (16), OMIM (http://www.omim.org) identity, and phenotypic assessment. PCR to amplify exon 24 and flanking regions of PIK3CD for Sanger sequencing was carried out using primers specific to the region. Purified PCR products were sequenced in both directions using an ABI PRISM 3130 genetic analyzer and aligned to reference sequence NM_005026.3.

\section{RESULTS}

In light of a non-diagnostic immunologic work-up and short stature (Table 1), an array-CGH was performed, which was uninformative. The family was consented and enrolled in the $\mathrm{CMH}$ undiagnosed disease program, where trio-exome sequencing was performed on a research basis, revealing a de novo pathogenic variant in PIK3CD, c.3061G >A (p.E1021L). Comparison of rare single-nucleotide variants between samples confirmed parentage. During the extended period of time over which the work-up was carried out, he developed chronic cervical lymphadenopathy and a pneumonia requiring intravenous antibiotics. Since his APDS diagnosis, he has been stably managed on immunomodulatory agents, and has not subsequently experienced an abscess, deep-seated infection, osteomyelitis, chronic diarrhea, fungal infection, or most importantly, a malignancy.

\section{DISCUSSION}

As illustrated by this case, it can be difficult enough to ensure any immunodeficiency is the cause of clinical findings, especially a diagnosis as seemingly obscure as APDS. The clinical and laboratory findings can be non-specific and variable. When the diagnosis is suspected, it can be confirmed with genetic testing if a pathogenic variant is present. As such a rarely diagnosed condition, treatment is not well established but has been reported that rapamycin rectifies the T-cell defect in vitro, increases naïve T-cell levels in vivo, and improves the clinical course (7). Selective p110-delta inhibitors have been shown to be effective in individuals with relapsing indolent lymphomas (17) and have been suggested as potentially effective agents for individuals with APDS, but have yet to be demonstrated as such in clinical trials (6). As an entity that presents such challenge, greater understanding both in terms of clinical presentation and consideration is necessary for ensuring detection with optimal frequency and expeditiousness. Having been described only recently, so few times, and with phenotypic heterogeneity; refinement of the understanding of the clinical manifestations is necessary. This case confirms previously reported features while clarifying previous assumptions. As in previous cases, our patient experienced recurrent upper and lower respiratory infections, lymphadenopathy, mucosal lymphoid proliferation, a low CD4:CD8, elevated levels of IgM, and low antibody titers following vaccination. Unlike most other cases, however, total immunoglobulin levels and levels of subtypes were within normal limits. Additionally, while he was heterozygous for the E1021K variant, genetic testing of his parents confirmed the variant to be de novo as compared with the majority of cases who inherited a variant from a parent.

Despite relative overall insignificance by comparison with common diagnoses, publication of rare entities is important, so that they are kept in mind and detected when present. This is especially true for cases such as this one. In which failure to diagnose early may have detrimental long-term outcomes. While otitis media and sinusitis are common in children, recurrence and pneumonia are less so and as in this case they should prompt etiological investigation. Although bronchiectasis is a consistent feature of this syndrome, it is conceivable that earlier diagnosis and treatment could prevent its development by reducing chronic inflammation. If this boy had been treated prior to the ileocecal mass proliferating to such a size, the resected segment of bowel could have been saved. Even though currently this may not be considered a life-altering consequence by some, as with any medical intervention the effects cannot be absolutely appreciated. The appendectomy, for example, which has long been regarded as relatively inconsequential, is now understood to potentially harbor unintended consequences (18). Diagnosis and treatment were optimal given the current ability to detect and treat this condition. Its recent discovery and rarity have prevented more frequent consideration, routine diagnostic work-up, and the establishment of a recommended evidence-based treatment regimen. With this syndrome already known to carry an increased risk for B-cell lymphomas and PIK3CD becoming increasingly implicated in oncogenesis, this represents an entity for which early diagnosis is particularly imperative (19-21).

Additionally, this case is useful for its demonstration of two clinical features that should prompt consideration of this diagnosis. Most PIDs produce severe phenotypes that result in diagnosis during the first year of life. This boy's genetic diagnosis was not made until he was 10 years of age, and the relative innocuousness 
prevented serious suspicion for the first 6 years of his life. Thus, this diagnosis should be higher on the differential when a PID is suspected in an older child.

\section{CONCLUDING REMARK}

Finally, this case draws much needed attention to lymphoid hyperplasia. Any lymph node large enough to warrant a biopsy is likely at least reactive with lymphoid hyperplasia. Since lymph node biopsies are most commonly done to exclude malignancy, in the absence of malignancy lymph nodes are usually described as hyperplastic and the cause is often assumed to result from an indeterminable etiology. As such, lymphoid hyperplasia has become associated with benignity and reason for cessation of investigation. This case demonstrates how lymphoid hyperplasia can actually present as a medical emergency by serving as a lead point for intussusception. While the presentation is not usually so dramatic, caution is still in order, particularly for this diagnosis. APDS is associated with lymphoid hyperplasia, lymphadenopathy, and the development of B-cell lymphomas in the second or third decade of life. Therefore, the appearance of a lymphoma in the context of a history of repeated biopsies of hyperplastic nodes should not be unexpected. For this reason, it is imperative that one maintain a high degree of suspicion despite repeatedly negative biopsies.

\section{REFERENCES}

1. Chantry D, Vojtek A, Kashishian A, Holtzman DA, Wood C, Gray PW, et al. p110delta, a novel phosphatidylinositol 3-kinase catalytic subunit that associates with p85 and is expressed predominantly in leukocytes. J Biol Chem (1997) 272:19236-41. doi:10.1074/jbc.272.31.19236

2. Vanhaesebroeck B, Welham MJ, Kotani K, Stein R, Warne PH, Zvelebil MJ, et al. P110delta, a novel phosphoinositide 3-kinase in leukocytes. Proc Natl Acad Sci U S A (1997) 94:4330-5. doi:10.1073/pnas.94.9.4330

3. Clayton E, Bardi G, Bell SE, Chantry D, Downes CP, Gray A, et al. A crucial role for the p110delta subunit of phosphatidylinositol 3-kinase in B cell development and activation. JExp Med (2002) 196:753-63. doi:10.1084/ jem.20020805

4. Okkenhaug K, Patton DT, Bilancio A, Garcon F, Rowan WC, Vanhaesebroeck B. The p110delta isoform of phosphoinositide 3-kinase controls clonal expansion and differentiation of Th cells. J Immunol (2006) 177:5122-8. doi:10.4049/ jimmunol.177.8.5122

5. Papakonstanti EA, Ridley AJ, Vanhaesebroeck B. The p110delta isoform of PI 3-kinase negatively controls RhoA and PTEN. EMBO J (2007) 26:3050-61. doi:10.1038/sj.emboj.7601763

6. Angulo I, Vadas O, Garcon F, Banham-Hall E, Plagnol V, Leahy TR, et al. Phosphoinositide 3-kinase delta gene mutation predisposes to respiratory infection and airway damage. Science (2013) 342:866-71. doi:10.1126/ science. 1243292

7. Lucas CL, Kuehn HS, Zhao F, Niemela JE, Deenick EK, Palendira U, et al. Dominant-activating germline mutations in the gene encoding the $\mathrm{PI}(3) \mathrm{K}$ catalytic subunit p110delta result in T cell senescence and human immunodeficiency. Nat Immunol (2014) 15:88-97. doi:10.1038/ni.2771

8. Jou ST, Chien YH, Yang YH, Wang TC, Shyur SD, Chou CC, et al. Identification of variations in the human phosphoinositide 3-kinase p110delta gene in children with primary B-cell immunodeficiency of unknown aetiology. Int J Immunogenet (2006) 33:361-9. doi:10.1111/j.1744-313X.2006.00627.x

9. Crank MC, Grossman JK, Moir S, Pittaluga S, Buckner CM, Kardava L, et al. Mutations in PIK3CD can cause hyper IgM syndrome (HIGM) associated with increased cancer susceptibility. J Clin Immunol (2014) 34:272-6. doi:10.1007/ s10875-014-0012-9

\section{ETHICS STATEMENT}

The Children's Mercy Hospitals and Clinics ethical committee approved this case report after being reviewed and satisfied all the sections of the rules and regulations for the research at $\mathrm{CMH}$ including the consent from the parents. Written consent has been obtained from the parents/legal guardians for publication.

\section{AUTHOR CONTRIBUTIONS}

$\mathrm{CS}, \mathrm{CD}$, and DM carried out data collection and drafted the manuscript. CS, IT, and DM carried out editing of the manuscript and contributed to reviewing the data. All authors read and approved the final manuscript.

\section{ACKNOWLEDGMENTS}

The authors are very grateful to this family for allowing this case to be published.

\section{FUNDING}

This work was supported by the Marion Merrell Dow Foundation, Children's Mercy-Kansas City, Black and Veatch, and the Clare Giannini Foundation.

10. Chiriaco M, Brigida I, Ariganello P, Di Cesare S, Di Matteo G, Taus F, et al. A case of APDS patient: defects in maturation and function and decreased in vitro anti-mycobacterial activity in the myeloid compartment. Clin Immunol (2015). doi:10.1016/j.clim.2015.12.008

11. Hartman HN, Niemela J, Hintermeyer MK, Garofalo M, Stoddard J, Verbsky JW, et al. Gain of function mutations of PIK3CD as a cause of primary sclerosing cholangitis. J Clin Immunol (2015) 35:11-4. doi:10.1007/s10875014-0109-1

12. Elgizouli M, Lowe DM, Speckmann C, Schubert D, Hulsdunker J, Eskandarian Z, et al. Activating PI3Kdelta mutations in a cohort of 669 patients with primary immunodeficiency. Clin Exp Immunol (2016) 183:221-9. doi:10.1111/ cei. 12706

13. Soden SE, Saunders CJ, Willig LK, Farrow EG, Smith LD, Petrikin JE, et al. Effectiveness of exome and genome sequencing guided by acuity of illness for diagnosis of neurodevelopmental disorders. Sci Transl Med (2014) 6: 265ra168. doi:10.1126/scitranslmed.3010076

14. Miller NA, Farrow EG, Gibson M, Willig LK, Twist G, Yoo B, et al. A 26-hour system of highly sensitive whole genome sequencing for emergency management of genetic diseases. Genome Med (2015) 7:100. doi:10.1186/s13073015-0221-8

15. Willig LK, Petrikin JE, Smith LD, Saunders CJ, Thiffault I, Miller NA, et al. Whole-genome sequencing for identification of Mendelian disorders in critically ill infants: a retrospective analysis of diagnostic and clinical findings. Lancet Respir Med (2015) 3:377-87. doi:10.1016/S2213-2600(15)00139-3

16. Richards S, Aziz N, Bale S, Bick D, Das S, Gastier-Foster J, et al. Standards and guidelines for the interpretation of sequence variants: a joint consensus recommendation of the American College of Medical Genetics and Genomics and the Association for Molecular Pathology. Genet Med (2015) 17:405-24. doi:10.1038/gim.2015.30

17. Gopal AK, Kahl BS, De Vos S, Wagner-Johnston ND, Schuster SJ, Jurczak WJ, et al. PI3Kdelta inhibition by idelalisib in patients with relapsed indolent lymphoma. N Engl JMed (2014) 370:1008-18. doi:10.1056/ NEJMoa1314583

18. Randal Bollinger R, Barbas AS, Bush EL, Lin SS, Parker W. Biofilms in the large bowel suggest an apparent function of the human vermiform appendix. J Theor Biol (2007) 249:826-31. doi:10.1016/j.jtbi.2007.08.032 
19. Zhang J, Grubor V, Love CL, Banerjee A, Richards KL, Mieczkowski PA, et al. Genetic heterogeneity of diffuse large B-cell lymphoma. Proc Natl Acad Sci US A (2013) 110:1398-403. doi:10.1073/pnas.1205299110

20. Bai H, Li H, Li W, Gui T, Yang J, Cao D, et al. The PI3K/AKT/mTOR pathway is a potential predictor of distinct invasive and migratory capacities in human ovarian cancer cell lines. Oncotarget (2015) 6:25520-32. doi:10.18632/ oncotarget. 4550

21. Cui W, Zheng S, Li X, Ma Y, Sang W, Liu M, et al. PIK3CD promoted proliferation in diffuse large B cell lymphoma through upregulation of c-myc. Tumour Biol (2016) 37:12767-77. doi:10.1007/s13277-016-5225-5
Conflict of Interest Statement: The authors declare that the research was conducted in the absence of any commercial or financial relationships that could be construed as a potential conflict of interest.

Copyright $\odot 2017$ Mettman, Thiffault, Dinakar and Saunders. This is an openaccess article distributed under the terms of the Creative Commons Attribution License (CC BY). The use, distribution or reproduction in other forums is permitted, provided the original author(s) or licensor are credited and that the original publication in this journal is cited, in accordance with accepted academic practice. No use, distribution or reproduction is permitted which does not comply with these terms. 